\title{
Improving accuracy and efficiency of early warning scores in acute care
}

\author{
MA Mohammed, R Hayton, G Clements, G Smith, D Prytherch
}

\begin{abstract}
Background: Early warning scores (EWS) are an integral part of the care of acutely ill patients. Unfortunately, in the few studies where the accuracy of EWS has been tested it has been found to be lacking, with serious implications for quality of care. Aim: to determine if the provision of computer-aided scoring could increase the accuracy and efficiency of EWS calculations, when compared with the traditional pen-and-paper method, and to determine if it was acceptable to users. Design: 26 nurses from two surgical assessment wards in two hospitals were studied. The study was conducted in three phases. Phase 1 - a classroom-based exercise where nurses were given ten patient vignettes and asked to derive EWS using traditional pen-andpaper methods; Phase 2 - the same as phase 1 , but using a hand-held computer to derive EWS; Phase 3 - the same as phase 2, but was a follow-up exercise undertaken in the ward environment, 4 weeks after computer-aided scoring was implemented in the two wards. Each phase closed with a user perception/attitudes questionnaire. Results: Accuracy and efficiency - phase 1 was associated with a significantly lower overall accuracy $(152 / 260,58 \%)$ compared with phase $2(96 \%$; difference in proportions $38 \%, 95 \%$ confidence interval $31-44 \%, P<0.0001)$. There was a small but significant reduction in accuracy from phase $2(96 \%)$ to phase $3(88 \%)(8 \%$ difference, $P=0.006)$. The mean time to derive an EWS reduced from 37.9 seconds in phase 1 to 35.1 seconds in phase $2(P=0.016)$, down to 24.0 seconds in phase $3(P<0.0001)$. User acceptability: in phase 1, nurses favoured the pen-and-paper method in all respects except accuracy. In phase 2, nurses' views shifted significantly in favour of the handheld computer, with little deterioration in the follow-up phase 3. Conclusions: a hand-held computer helps to improve the accuracy and efficiency of EWS in acute hospital care and is acceptable to nurses.
\end{abstract}

Key words: Acute care - Critical care " Early warning score " Vital signs

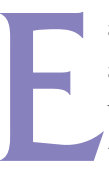

arly warning scores (EWS), also known as 'track and trigger' systems, are in widespread use in acute hospital care to aid the early detection of patient deterioration (Morgan et al, 1997; Stenhouse et al, 2000; Hodgetts et al, 2002; Goldhill et al, 2005). They operate by allotting points to patients' routine vital signs measurements on the basis of physiological derangement from a predetermined 'normal' range. These points are summed to provide an EWS for a patient.

The rationale for the use of an EWS is that early recognition of deterioration in the vital signs of a patient can afford opportunities for earlier, more effective intervention (Lundberg et al, 1998; Rivers et al, 2001; Sebat et al, 2005; DeVita et al, 2006). Typically in the UK the initial intervention takes the form of a 'critical care outreach' team (McArthur-Rouse, 2001; Bright et al, 2004), which is usually called when the EWS reaches arbitrarily predefined thresholds.
Unfortunately, there is only minimal evidence that patient outcomes have improved as a result of the introduction of EWS systems (Robson, 2002; Ball et al, 2003; Cuthbertson, 2003; Subbe et al, 2003; Priestley et al, 2004). One plausible interpretation is that inaccurate calculation of EWS undermines the effectiveness of the EWS outreach process (Prytherch et al, 2006; Smith and Oakey, 2006; Subbe et al, 2006). The primary aim of this study was to determine if the provision of computeraided scoring could increase the accuracy and efficiency of EWS calculations, when compared with the traditional pen-andpaper method. The study also sought to elicit user acceptability of the computeraided approach.

\section{Methods}

The study participants were the full compliment of nurses $(n=26)$ based on two surgical assessments units (SAU) in Shrewsbury and Telford Hospitals NHS Trusts. These two units were chosen because they had previous experience of EWS using pen-and-paper methods and also their senior clinical staff volunteered participation. Informed consent was obtained from each nurse before enrolment and nurse confidentiality was guaranteed. Local Research Ethics Committee approval was obtained for the study. The study was conducted in three phases:

Phase 1: undertaken in a classroom setting, 26 nurses were asked to derive an EWS from each of ten patient vignettes (i.e. five paired sets) with true EWS values of 1, 3, 5, 8 and 9 points using traditional pen-and-paper methods only. The EWS, which has been in use in the hospitals for at least 3 years, is illustrated in Table 1. Phase 1 closed with the nurses completing a user perceptions/attitude questionnaire, which elicited their views regarding the potential use of computeraided EWS scoring calculation versus the traditional pen-and-paper method.

Phase 2: this was similar to phase 1 and was again undertaken in a classroom setting. 


\section{Table 1. Early warning scoring system used in the study}

\begin{tabular}{|c|c|c|c|c|c|c|c|}
\hline Vital sign & 3 & 2 & 1 & 0 & 1 & 2 & 3 \\
\hline Conscious level & & & & Alert & $\begin{array}{l}\text { Drowsy or } \\
\text { responds } \\
\text { to voice }\end{array}$ & $\begin{array}{l}\text { Confused or } \\
\text { responds } \\
\text { to pain }\end{array}$ & $\begin{array}{l}\text { To pain only or } \\
\text { unresponsive }\end{array}$ \\
\hline Respiratory rate per minute & $<=6$ & $6-8$ & & $9-16$ & $17-22$ & $23-29$ & $>=30$ \\
\hline Heart rate per minute & $<=40$ & $41-50$ & & $51-100$ & $101-110$ & $111-129$ & $>=130$ \\
\hline Blood pressure systolic & $<=80$ & $81--90$ & $91-100$ & $101-199$ & & $>=200$ & \\
\hline Urine (mls) over 4 hours & & & & $>=120$ & $<120$ & $<=40$ & $<=20$ \\
\hline
\end{tabular}

EWS were now derived with the aid of a hand-held computer. This phase began with each nurse undergoing a 45-minute, handson training exercise using the hand-held computer with a trainer/facilitator. Phase 2 closed with the nurses completing the same user perception/attitudes questionnaire as in phase 1.

Phase 3: a follow-up exercise, similar in design to phase 2, except that it was carried out 4 weeks after the nurses had used computer-aided scoring routinely in the two SAUs. For phase 3, nurses were required to derive EWS with the aid of the hand-held computer in the ward environment. Only 20 of the original 26 nurses participated in phase 3 (six nurses had left to work in other wards). In all phases, the patient scenarios were presented in the same order.

The two methods (pen-and-paper versus computer-aided scoring) were compared in three ways:
- Accuracy of EWS calculation. This was defined as the proportion of correctly derived early warning scores.

- Time taken to derive an EWS per patient scenario. This was measured with 13 nurses only (from one SAU) because of resource constraints.

- User perceptions/attitudes. These were elicited using a questionnaire. Nurses were asked to score the following statements using a five-point Likert scale, ranging from 'strongly disagree' to 'strongly agree' (1-5 respectively, with scores $>3$ indicating preference for the hand-held computer):

1. I think that I will prefer the pen-and-paper method to the hand-held computer

2. I think that the pen-and-paper method will be faster/speedier than the handheld computer

3. I think that the pen-and-paper method will be simpler than the hand-held computer
4.I think that the pen-and-paper method will be more convenient than the handheld computer

5.I think that the pen-and-paper method will be more accurate than the hand-held computer.

Additionally, nurses were asked to state their concerns regarding, and to describe the perceived benefits of, computer-aided EWS calculation.

\section{Computer-aided support}

Computer-aided scores were derived using a specially programmed, hand-held computer, VitalPAC (The Learning Clinic Ltd, London). VitalPAC is a user-friendly touchscreen application designed to facilitate the collection of vital sign measurements and the derivation of a subsequent EWS by nurses in the clinical setting. The VitalPAC did not require the participant to know the weighting scale of the EWS system. Further details

Images courtesy of The Learning Clinic Ltd. Not to be reproduced without permission.
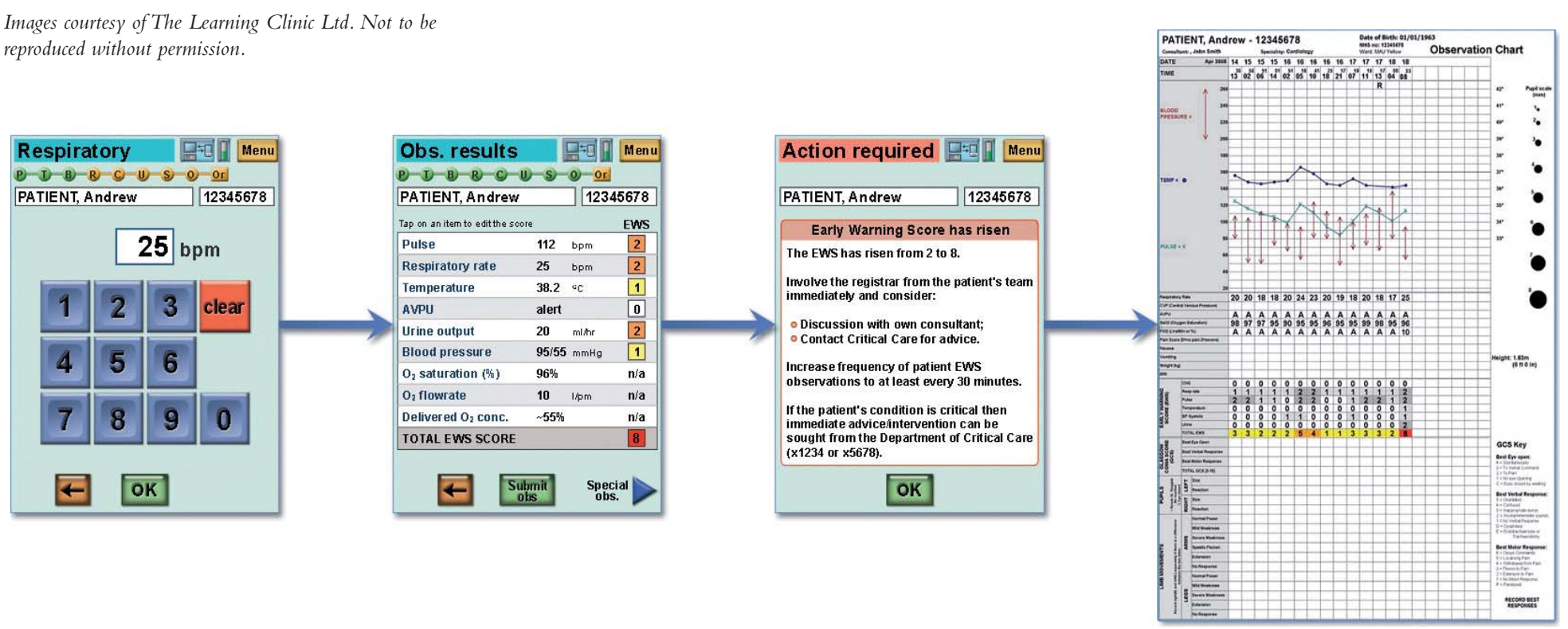

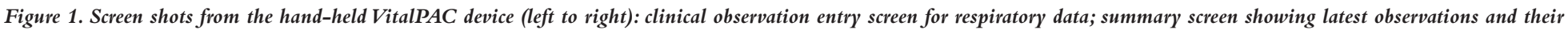
associated early warning score (EWS); action screen depending on the total EWS and finally a print out of clinical observations on paper. The data is for a fictitious patient. 


\section{Table 2. Accuracy of calculations of early warning scores (EWS) derived for each patient scenario over three phases}

\begin{tabular}{|c|c|c|c|c|c|c|c|}
\hline \multirow[t]{2}{*}{$\begin{array}{l}\text { Patient } \\
\text { scenario }\end{array}$} & \multirow[t]{2}{*}{$\begin{array}{l}\text { True } \\
\text { EWs }\end{array}$} & \multicolumn{2}{|c|}{$\begin{array}{l}\text { Phase 1: pen and paper } \\
(n=26)\end{array}$} & \multicolumn{2}{|c|}{$\begin{array}{l}\text { Phase 2: Computer-aided } \\
(\mathrm{n}=26)\end{array}$} & \multicolumn{2}{|c|}{$\begin{array}{c}\text { Phase 3: } \\
\text { Computer-aided follow-up } \\
(n=20)\end{array}$} \\
\hline & & Number correct & $\%$ correct & Number correct & $\%$ correct & Number correct & $\%$ correct \\
\hline 1 & 1 & 21 & 81 & 26 & 100 & 19 & 95 \\
\hline 2 & 3 & 16 & 62 & 26 & 100 & 19 & 95 \\
\hline 3 & 5 & 18 & 69 & 24 & 92 & 13 & 65 \\
\hline 4 & 9 & 5 & 19 & 25 & 96 & 13 & 68 \\
\hline 5 & 8 & 15 & 58 & 25 & 96 & 15 & 75 \\
\hline 6 & 1 & 17 & 65 & 26 & 100 & 20 & 100 \\
\hline 7 & 3 & 20 & 77 & 24 & 92 & 20 & 100 \\
\hline 8 & 5 & 21 & 81 & 24 & 92 & 18 & 90 \\
\hline 9 & 9 & 7 & 27 & 25 & 96 & 19 & 95 \\
\hline 10 & 8 & 12 & 12 & 25 & 96 & 19 & 95 \\
\hline Total & & $152 / 260$ & 58 & $250 / 260$ & 96 & $175 / 200$ & 88 \\
\hline
\end{tabular}

of VitalPAC have been reported elsewhere (Smith et al, 2006). Figure 1 shows the device and its ability to produce computer-based clinical observation charts.

\section{Statistical analysis}

Statistical analyses (P-values and 95\% confidence intervals [CI]) were undertaken using methods for paired samples (t-test and McNemar's test for paired samples). The primary comparisons were: phase 1 versus phase 2 , and phase 2 versus phase 3 .

\section{Results}

\section{Accuracy}

Table 2 shows the accuracy of EWS calculations for each phase of the study. Phase 1, the pen-and-paper method, was associated with a significantly lower overall accuracy $(152 / 260,58 \%)$ compared with phase 2 (computer-aided support, 96\%; difference in proportions 38\%, 95\% CI $31-44 \%, P<0.0001$ McNemar's test).

Accuracy in phase $3(175 / 200,88 \%)$ was reduced compared with phase 2 , primarily by low scores for patient scenarios 3-5

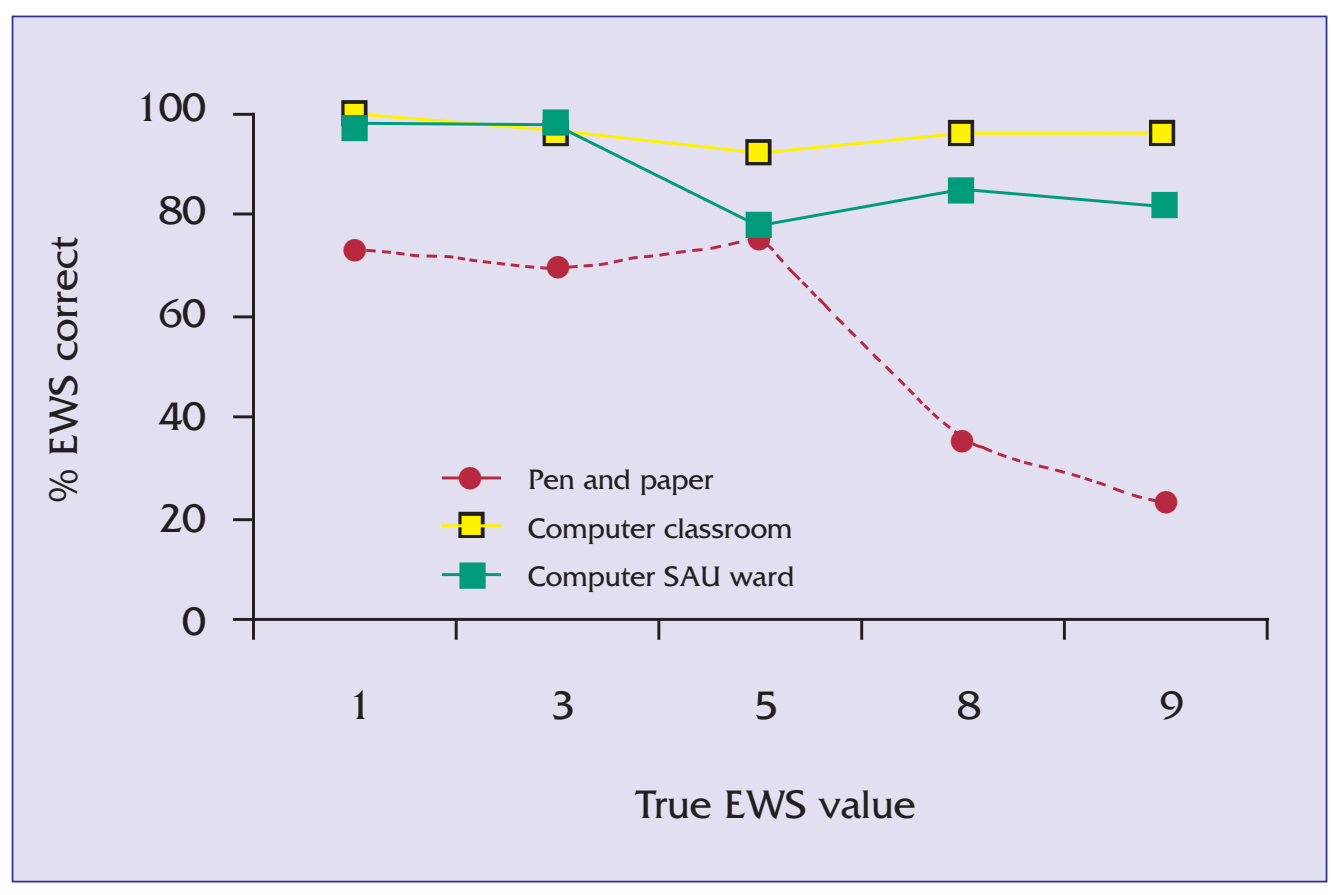

Figure 2. Average accuracy of early warning score (EWS) calculations related to value of true EWS. (difference from phase 2=8\%, 20 nurses; 95\% CI $2-17 \%, P=0.006$ McNemar's test).

Figure 1 shows the relationship between average accuracy of EWS calculations and the value of the true EWS. The patterns for phases 2 and 3 were broadly similar; however, for the pen-and-paper method, the average accuracy of EWS calculations reduced significantly as the value of the true EWS, and therefore patient severity of illness, increased. The average difference between the true EWS and the score derived using the pen-and-paper method (phase 1) was 0.67 (standard deviation $[\mathrm{SD}]=0.93)$, compared with $0.07(\mathrm{SD}=0.40)$ in phase 2 (difference in phase 1 versus phase 2 : 0.6 paired t-test $\mathrm{t}=9.5, P<0.0001,95 \% \mathrm{CI}$ $0.5-0.7)$ and $0.16(\mathrm{SD}=0.56)$ in phase 3 (difference in phase 2 versus phase 3: 0.09, $95 \%$ CI $0-0.2, \mathrm{t}=2.1, P=0.043)$.

\section{Timing}

Data regarding the time taken for nurses to derive an EWS per patient scenario were available from only 13 nurses. The mean time reduced from 37.9 (median 35.5) seconds in phase 1 to 35.1 (median 33.5) seconds in phase 2 (paired t-test for means, $\mathrm{t}=2.43$; $P=0.016$ ), and 24.0 (median 25.3) seconds in phase 3 (paired t-test for mean, $\mathrm{t}=8.7$; $P<0.0001$ ) (Figure 2).

Figure 3 shows the relationship between the time taken for nurses to derive an EWS and the value of the true EWS for each phase of the study.

When using pen and paper (phase 1), 
patient scenarios with higher true EWS took longer to derive. This relationship was not observed with computer-aided scoring. Calculations undertaken in phase 3 were faster and showed less variability than in either of the other phases.

\section{Nurse perceptions}

In phase 1, nurses favoured the pen-and-paper method (mean score $<=3$ ) in all respects except accuracy (Table 3) where the mean score was 3.27. In phase 2 , nurses' views shifted significantly and overwhelmingly in favour of the hand-held computer, with little deterioration in the follow-up phase 3 .

Some of the concerns which nurses reported in free text form during phase 3, included:

- Concern about the reliability of the equipment (e.g. under a power failure)

- The increased burden in maintaining paper and hand-held EWS during the pilot study period

- Feeling this might de-skill some nurses.

Some of the benefits reported by nurses during phase 3 were that the hand-held: (a) increased accuracy, (b) was less time consuming and (c) could improve communication with other healthcare professionals.

\section{Discussion}

Despite their widespread use in identifying sick patients and initiating appropriate care, the quality of EWS has received only minimal attention (Prytherch et al, 2006; Smith and Oakey, 2006; Subbe et al, 2006).

The present study clearly demonstrates that the traditional pen-and-paper method of deriving scores is less accurate and takes
Figure 3. Box plot showing times (seconds) to derive an early warning score in three phases. Filled circle in box indicates median.

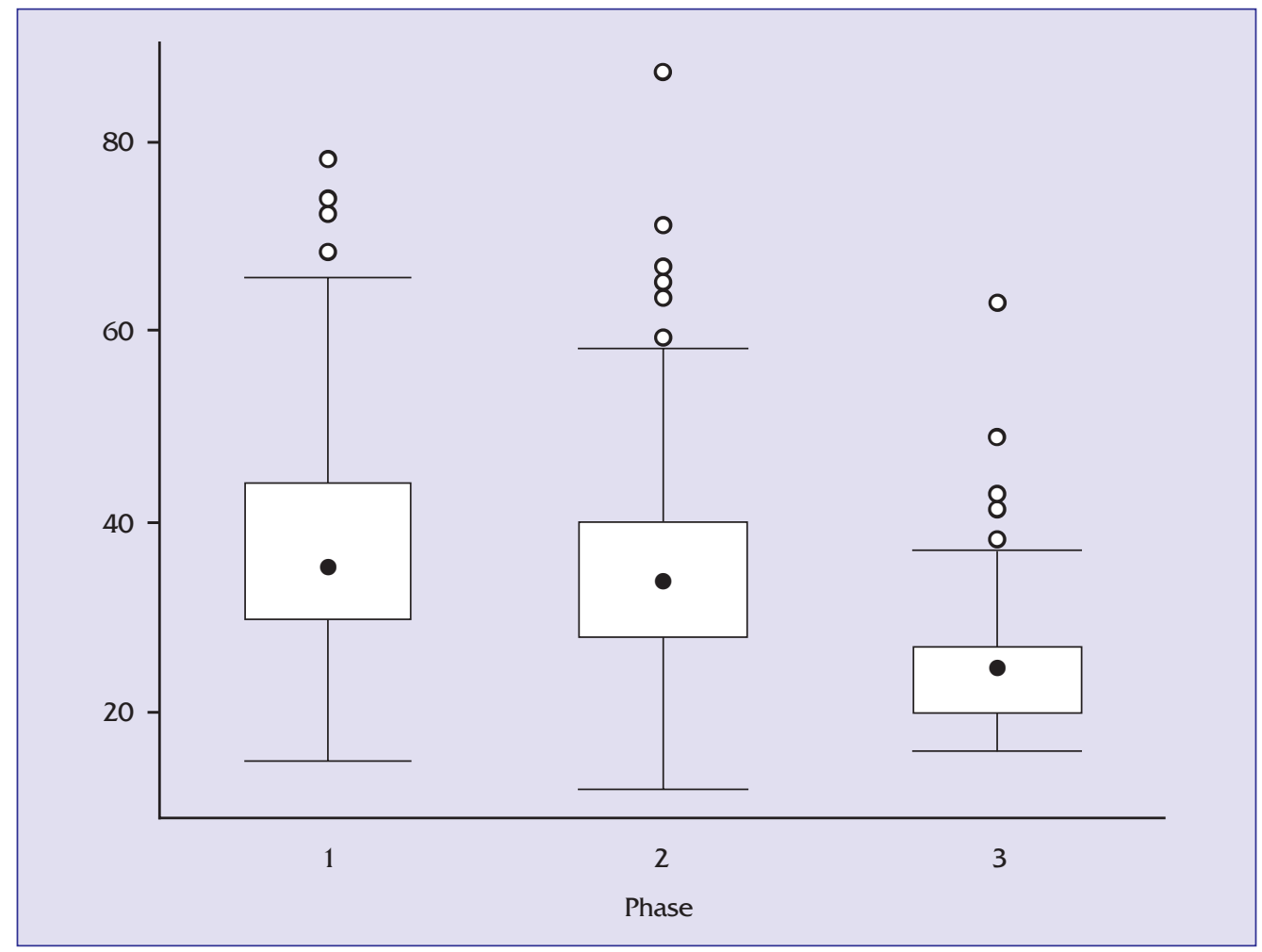

longer than those aided by a computer. There are several possible factors that may explain these findings. It is well documented that skills in mental mathematics in the UK population as a whole (BBC, 2002), and nurses in particular (Hutton, 1998; BBC, 2000), are deficient.

Therefore, while it might be tempting to think that the long-term solution is to improve mental mathematics training, this would miss the point that there are many distractions to mental tasks in a busy ward environment. It would also fail to recognize that the problem is endemic and that educational interventions (which have been the subject of much research) to improve this skill will take some time to filter through to front line healthcare. Furthermore, a rationale for increasing reliance on computers is that it should release humans from the need to undertake mundane tasks, while allowing them to concentrate on higher-order tasks

\section{Table 3. Mean (standard deviation) score of nurses to five statements seeking their views on comparing pen and paper to the hand-held computer. Mean scores $>3$ favour the hand-held computer}

\begin{tabular}{|c|c|c|c|c|}
\hline Statement & $\begin{array}{l}\text { Phase 1: } \\
\text { pen and paper } \\
(n=26)\end{array}$ & $\begin{array}{l}\text { Phase 2: } \\
\text { Computer-aided } \\
(n=26)\end{array}$ & $\begin{array}{l}\text { Phase 3: } \\
\text { Computer-aided } \\
\text { follow-up } \\
(n=20)\end{array}$ & $\begin{array}{l}\text { Phase } 1 \\
\text { versus } \\
\text { Phase } 2\end{array}$ \\
\hline $\begin{array}{l}\text { I think that I will prefer the pen-and-paper method } \\
\text { to the hand-held computer }\end{array}$ & $\begin{array}{l}2.58 \\
(1.1)\end{array}$ & $\begin{array}{l}3.88 \\
(1.2)\end{array}$ & $\begin{array}{l}3.85 \\
(1.1)\end{array}$ & $\begin{array}{l}t=4.2 \\
P<0.001\end{array}$ \\
\hline $\begin{array}{l}\text { I think that the pen-and-paper method will be } \\
\text { faster/speedier than the hand-held computer }\end{array}$ & $\begin{array}{l}2.77 \\
(1.3)\end{array}$ & $\begin{array}{l}3.73 \\
(1.3)\end{array}$ & $\begin{array}{l}3.45 \\
(1.3)\end{array}$ & $\begin{array}{l}t=3.4 \\
P=0.002\end{array}$ \\
\hline $\begin{array}{l}\text { I think that the pen-and-paper method will be simpler } \\
\text { than the hand-held computer }\end{array}$ & $\begin{array}{l}2.58 \\
(1.2)\end{array}$ & $\begin{array}{l}4.08 \\
(1.4)\end{array}$ & $\begin{array}{l}4.05 \\
(1.1)\end{array}$ & $\begin{array}{l}t=5.1 \\
P<0.001\end{array}$ \\
\hline $\begin{array}{l}\text { I think that the pen-and-paper method will be more } \\
\text { convenient than the hand-held computer }\end{array}$ & $\begin{array}{l}2.58 \\
(1.2)\end{array}$ & $\begin{array}{l}3.77 \\
(1.5)\end{array}$ & $\begin{array}{l}3.70 \\
(1.2)\end{array}$ & $\begin{array}{l}t=3.6 \\
P=0.001\end{array}$ \\
\hline $\begin{array}{l}\text { I think that the pen-and-paper method will be more } \\
\text { accurate than the hand-held computer }\end{array}$ & $\begin{array}{l}3.27 \\
(1.0)\end{array}$ & $\begin{array}{l}4.15 \\
(1.0)\end{array}$ & $\begin{array}{l}4.40 \\
(0.9)\end{array}$ & $\begin{array}{l}t=3.3 \\
P=0.03\end{array}$ \\
\hline
\end{tabular}


Figure 4. Box plot showing times (seconds) to derive an early warning score in each phase of the study (phases 1-3 shown from left to right).

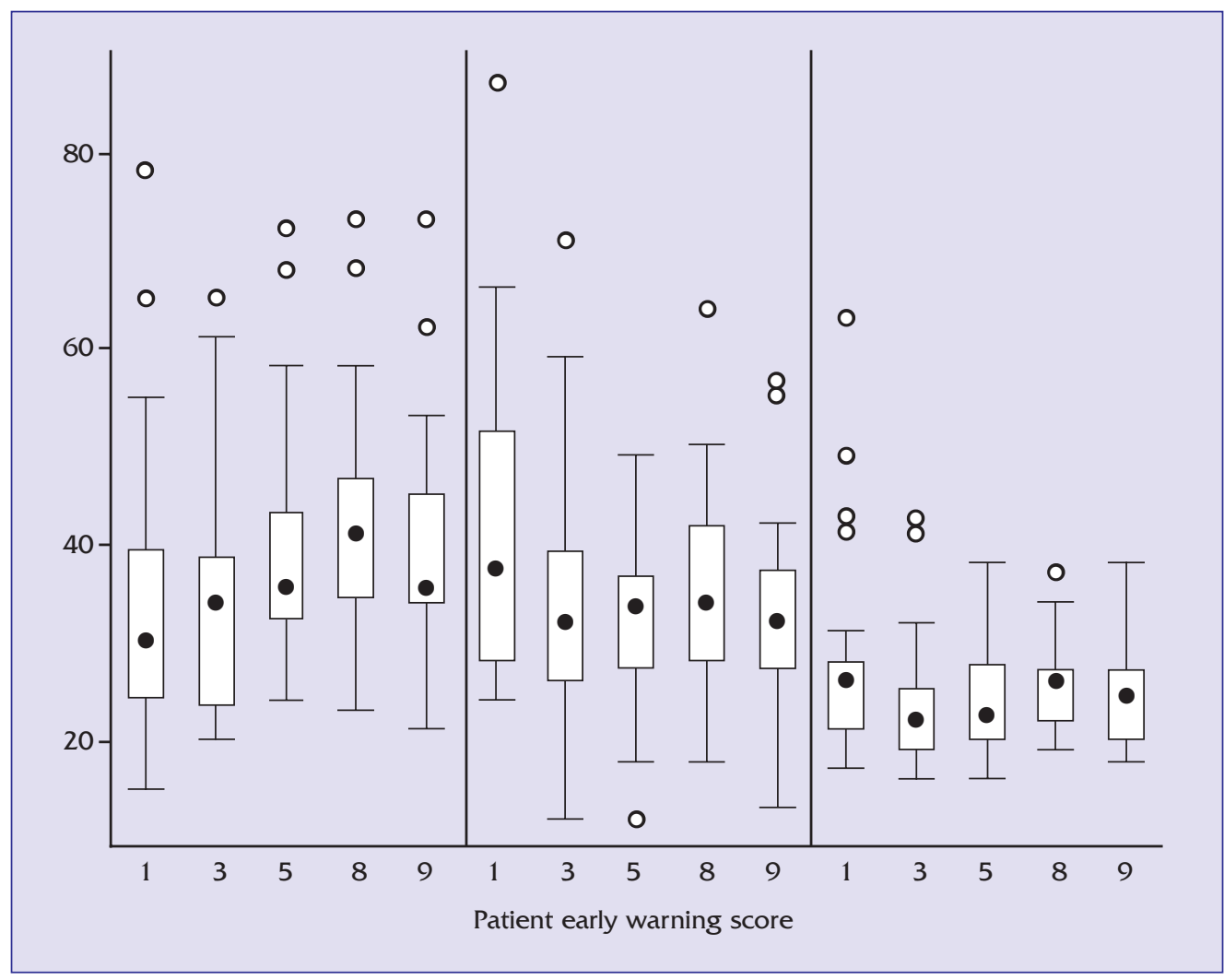

(Payne, 2000). The accuracy and timings found in this study correlate well with data from a previous classroom exercise (Prytherch et al, 2006), suggesting that the shortcomings of the pen-and-paper method, and the benefits of computer-aided EWS are, to some extent, generalizable.

In the classroom environment, computeraided scoring in the present study was faster and achieved accuracy nearing 100\%. Perhaps more importantly, it was found that EWS derived in a ward are associated with lower accuracy, even with the aid of a handheld computer. Further work is required to understand the sources of these errors and the constraints on achieving 100\% accuracy with the hand-held computer. It is noted that penand-paper methods can also be influenced by factors in the ward environment.

Smith and Oakely (2006) found that the accuracy of pen-and-paper-derived EWS degrades when the ward is busier. They also report that the true EWS affects the accuracy of calculated EWS. The present study also revealed a tendency towards greater inaccuracy and slower EWS calculation in patient vignettes with a higher true EWS (i.e. sicker patients). This was most marked with pen-and-paper methods, but was also noticeable to a lesser extent with the computer-aided approach. This is perhaps not surprising, because the laws of probability dictate that the total likelihood of error must increase as the number of abnormal values in the EWS that have to be processed increases. A similar relationship between speed of EWS calculation and true EWS has been reported elsewhere (Smith et al, in press). There also seems to be significant inter- and intra-variability in the reliability of manual EWS calculations (Subbe et al, 2006).

An important finding from the present study was the reduction in times taken to derive an EWS. Not only did the computer-aided method prove to be quicker in the classroom, but the input became faster with increased use. will eventually plateau, although it is not clear when this occurs. Nevertheless, the authors estimate that on average a nurse will save about 12 seconds per EWS, which escalates to about 76 days in a year (based on three EWS measurements per patient per day in a 500bedded hospital). It is important to consider the resource implications, because of the intense workload pressures on nurses, which is often amplified by nurse shortages (Medical News Today, 2006).

A critical issue in the introduction of a computer-aided solution is user perception and acceptability. In general, it was found that nurses were positive about the handheld computer and its contribution to Of course, it is anticipated that performance deriving an EWS. In the words of one newly qualified nurse, 'I have found this a most useful tool to assist in the care of my patients'. A small minority of nurses felt that the computer-aided approach might de-skill them. This requires further study, because the specific nature of the de-skilling was not specified, although it is unlikely to reflect the low-level mental arithmetic required to derive an EWS.

\section{Conclusion}

This study has shown how the derivation of EWS can be improved using an approach that is more accurate, efficient and acceptable to nurses than the traditional pen-and-paper method. While this in an important finding, the implications for clinical practice need to be assessed, but the positive feedback from nurses indicates that this solution to improving EWS should not be underestimated and clearly merits further research and development.

Conflicts of interests: VitalPAC is a collaborative development of The Learning Clinic Ltd and Portsmouth Hospitals NHS Trust. GBS, DP and $M A M$ contributed to the development of VitalPAC and members of the families of GBS and DP are creditors of The Learning Clinic Ltd.

Acknowledgments: The authors wish to express their thanks to the participating nurses, Carole Tune, Julie Lloyd, Jan Ibrahim, Roger Killen and Simon Kirk for their valuable help in undertaking this study.

Ball C, Kirkby M, Williams S (2003) Effect of the critical care outreach team on patient survival to discharge from hospital and readmission to critical care: non-randomised population based study. BMJ 327(7422): 1014-17

BBC (2000) GCSE maths blamed for nurses'blunders. BBC News, 15 June http://tinyurl.com/5u77t9 (accessed 8 Dec 2008)

BBC (2002) Bad maths blights bank holidays. BBC News, 5 May. Available at: http://tinyurl.com/5lf6bt (accessed 8 Dec 2008)

Bright D, Walker W, Bion J (2004) Clinical review: outreach - a strategy for improving the care of the acutely ill hospitalized patient. Crit Care 8(1): 33-40

Cuthbertson BH (2003) Outreach critical care - cash for no questions? Br J Anaesth 90(1): 4-6

Devita MA, Bellomo R, Hillman K et al (2006) Findings of the first consensus conference on medical emergency teams. Crit Care Med 34(9): 2463-78

Goldhill DR, McNarry AF, Mandersloot G, McGinley A (2005) A physiologically-based early warning score for ward patients: the association between score and outcome. Anaesthesia 60(6): 547-53

Hodgetts TJ, Kenward G,Vlachonikolis IG, Payne S, Castle N (2002) The identification of risk factors for cardiac arrest and formulation of activation criteria to alert a medical emergency team. Resuscitation 54(2): 125-31

Hutton B (1998) Nursing mathematics: the importance of application. Nurs Stand 13(11): 35-8

Lundberg JS, Perl TM, Wiblin T et al (1998) Septic shock: an analysis of outcomes for patients with onset on hospital wards versus intensive care units. Crit Care Med 26(6): 
wards versus intensive care units. Crit Care Med 26(6): 1020-4

McArthur-Rouse F (2001) Critical care outreach services and early warning scoring systems: a review of the literature. J Adv Nurs 36(5): 696-704

Medical News Today (2006) Senior nurses struggling under pressure of NHS deficits and pace of reforms, UK. Medical News Today, 29 April.Available at: http://tinyurl. com/5omxem (accessed 8 Dec 2008)
Morgan R, Williams F, Wright M (1997) An early warning scoring system for detecting developing critical illness. Clin Intensive Care 8(2): 100

Payne HD (2000) Computer decision support systems. Chest 118(2 Suppl): 47S-52S

Priestley G, Watson W, Rashidian A et al (2004) Introducing Critical Care Outreach: a ward-randomised trial of phased introduction in a general hospital. Intensive Care Med 30(7): 1398-404

\section{KEY POINTS}

Early warning scores (EWS) are an integral part of the care of acutely ill patients.

A study was undertaken to determine if the provision of computer-aided scoring could increase the accuracy and efficiency of EWS calculations, when compared with the traditional pen-and-paper method, and to determine if it was acceptable to users.

- The study was conducted in three phases: in phase 1 , nurses favoured the pen-and-paper method in all respects except accuracy. In phase 2, nurses' views shifted significantly in favour of the hand-held computer, with little deterioration in the follow-up phase 3.

- An important issue when introduction a computer-aided solution is user perception and acceptability. In general, it was found that nurses were positive about the hand-held computer and its contribution to deriving an EWS.

- This study has shown how the derivation of EWS can be improved using an approach that is more accurate, efficient and acceptable to nurses than the traditional pen-and-paper method.

Prytherch DR, Smith GB, Schmidt P et al (2006) Calculating early warning scores - classroom comparison of pen and paper and hand-held computer methods. Resuscitation 70(2): 173-8

Rivers E, Nguyen B, Havstad S et al (2001) Early goaldirected therapy in the treatment of severe sepsis and septic shock. N Engl J Med 345(19): 1368-77

Robson WP (2002) An evaluation of the evidence base related to critical care outreach teams -2 years on from Comprehensive Critical Care. Intensive Crit Care Nurs 18(4): 211-18

Sebat F, Johnson D, Musthafa AA et al (2005) A multidisciplinary community hospital program for early and rapid resuscitation of shock in nontrauma patients. Chest 127(5): 1729-43

Smith AF, Oakey RJ (2006) Incidence and significance of errors in a patient 'track and trigger' system during an epidemic of Legionnaires' disease: retrospective casenote analysis. Anaesthesia 61(3): 222-8

Smith GB, Prytherch DR, Schmidt P (2006) Hospitalwide physiological surveillance - a new approach to the early identification and management of the sick patient. Resuscitation 71(1): 19-28

Smith GB, Prytherch DR, Peet H et al (2008/9) Integrated monitoring and analysis for early warning of patient deterioration. $\mathrm{Br} J$ Anaesth (in press)

Stenhouse C, Coates S, Tivey M, Allsop P, Parker T (2000) Prospective evaluation of a modified Early Warning Score to aid earlier detection of patients developing critical illness on a general surgical ward. Br J Anaesth 84(5): 663 Subbe CP, Davies RG,Williams E, Rutherford P, Gemmell L (2003) Effect of introducing the Modified Early Warning score on clinical outcomes, cardio-pulmonary arrests and intensive care utilisation in acute medical admissions. Anaesthesia 58(8): 797-802

Subbe CP, Gao H, Harrison DA (2006) Inter- and intrarater reliability of physiological track and trigger warning systems. Intensive Care Med 32(suppl 1): S164 
Copyright of British Journal of Nursing (BJN) is the property of Mark Allen Publishing Ltd and its content may not be copied or emailed to multiple sites or posted to a listserv without the copyright holder's express written permission. However, users may print, download, or email articles for individual use. 